\title{
Evaluation of sequential multiplex PCR for direct detection of multiple serotypes of Streptococcus pneumoniae from nasopharyngeal secretions
}

\author{
Martin Antonio, ${ }^{1}$ Ishrat Hakeem, ${ }^{1}$ Kawsu Sankareh, ${ }^{1}$ Yin Bun Cheung ${ }^{2}$ \\ and Richard A. Adegbola ${ }^{1}$ \\ ${ }^{1}$ Bacterial Diseases Programme, Medical Research Council (MRC) Laboratories, Banjul, \\ The Gambia \\ ${ }^{2}$ Department of Infectious and Tropical Diseases, London School of Hygiene and Tropical Medicine, \\ London, UK
}

Correspondence

Martin Antonio

mantonio@mrc.gm

Received 21 August 2008

Accepted 31 October 2008

\begin{abstract}
Sequential multiplex PCR was evaluated for detection of multiple Streptococcus pneumoniae serotypes directly from nasopharyngeal secretions. A total of 279 nasopharyngeal swab samples were tested blindly. When limited to the 29 serotypes identifiable by the molecular method, the mean number of serotypes identified by the conventional latex/Quellung method was 0.85 , which was significantly lower than that by the molecular method $(P<0.0001)$. The multiplex PCR method identified significantly more serotypes than the latex/Quellung method if limited to the 29 serotypes ( $P=0.001$ and $P=0.014$, respectively).
\end{abstract}

\section{INTRODUCTION}

Pneumonia is a frequent cause of childhood deaths in many developing countries and its leading cause is Streptococcus pneumoniae infection (Berkley et al., 2005; Enwere et al., 2006; Greenwood, 1999; Scott, 2007; Scott et al., 2008; Shann, 1986). The pneumococcus is also a major cause of otitis media, responsible for morbidity in young children worldwide (Berman, 1995). Human immunodeficiency virus infection increases susceptibility to pneumococcal infection and, as a consequence, the incidence of pneumococcal infection in children and adults is increasing in many parts of sub-Saharan Africa (Jones et al., 1998; Madhi et al., 2000).

Streptococcus pneumoniae is subdivided into 91 different serotypes (Park et al., 2007), all of which are capable of causing invasive disease. Geographical variations in the distribution of pneumococcal serotypes exist, and some serotypes are associated selectively with disease in children or adults (Hausdorff et al., 2000).

Asymptomatic nasopharyngeal carriage of pneumococci is common in many developing countries where colonization of the nasopharynx with pneumococci commences shortly after birth (Gratten et al., 1986; Hill et al., 2008), and by the age of 2 years, almost all children are carriers (Frederiksen \& Henrichsen, 1988; Hill et al., 2008; Lloyd-Evans et al., 1996). In The Gambia, the prevalence of Streptococcus pneumoniae carriage among children aged $<1$ year was found to be $97 \%$, and the rate was $93 \%$ among babies aged $<1$ month and decreased with increasing age (Hill et al., 2006). Furthermore, the mean age of first acquisition of
Streptococcus pneumoniae carriage was 33 days, and nonvaccine types were acquired faster and were carried for a shorter duration than vaccine serotypes (Hill et al., 2008). Others have shown that recently acquired serotypes cause invasive disease (Gray et al., 1980; Syrjären et al., 2005), although the relationship between carriage and invasive disease is not fully understood.

Numerous studies have shown a reduction in the prevalence of nasopharyngeal carriage of pneumococci of vaccine types after immunization with pneumococcal conjugate vaccine (Dagan et al., 2003; Mbelle et al., 1999; Obaro et al., 1996, 2000; Whitney et al., 2003). However, this was accompanied by an increase in the carriage rate of pneumococci of non-vaccine types as a result of replacement or unmasking of previously unidentified pneumococci (Dagan et al., 2003; Ghaffar et al., 2004; Klugman, 2001; O'Brien et al., 2003). The long-term effects of vaccines that protect against some but not all pneumococcal serotypes remain uncertain. Therefore, it is important to have continuing surveillance of pneumococcal serotypes from invasive and carriage sources.

The use of pneumococcal colonization as a non-disease biological (but not surrogate) end point for licensure of vaccine products, rather than disease end points, is a new strategy that could improve the accuracy of the licensure process and significantly reduce the time for product evaluation and the cost of product development (http:// www.ktl.fi/roko/pneumocarr/index.html). In addition, non-disease biological end points could also enhance the process of new product development efforts by early 
decisions to target products for further development or rule out unsuitable candidate products. However, current methods are inadequate for studying colonization by multiple serotypes of Streptococcus pneumoniae. True carriage rates of multiple serotypes are not known because the methods for detecting multiple serotypes have relied mainly on picking several colonies directly from a culture plate for serotyping. Thus more robust methods are needed, particularly for assessing the impact of vaccines on the ecology of bacterial carriage. Pai et al. (2006) have developed a seven-step sequential multiplex PCR assay that is capable of distinguishing 29 pneumococcal serotypes/ serogroups, and this scheme has now been expanded to 33 serotypes (http://www.cdc.gov/ncidod/biotech/strep/pcr. $\mathrm{htm})$. Recently, this assay was evaluated on cultured invasive pneumococcal serotypes from Brazil (Dias et al., 2007) and Mozambique (Morais et al., 2007), but this assay targets single serotypes. The aim of the current study was to evaluate the utility of this sequential multiplex PCR for detection of multiple Streptococcus pneumoniae serotypes directly from nasopharyngeal samples (without enrichment or culture) during a trial of a seven-valent pneumococcal conjugate vaccine in The Gambia.

\section{METHODS}

Nasopharyngeal swab specimens. A cross-sectional survey of pneumococcal carriage was undertaken in 21 villages in the Western Division of The Gambia, as described previously (Hill et al., 2006). Nasopharyngeal swabs were collected and immediately inoculated into vials containing skimmed milk-tryptone-glucose-glycerol (STTG) transport medium, and placed in a cold box before transfer to the MRC Laboratories, Banjul, The Gambia, within $8 \mathrm{~h}$ of collection as recommended by the World Health Organization protocol for evaluation of pneumococcal carriage (O'Brien \& Nohynek, 2003). Inoculated vials were stored at $-70{ }^{\circ} \mathrm{C}$ until tested in batches by subculture onto gentamicin-blood agar for isolation of Streptococcus pneumoniae. Pneumococci were identified by morphology and optochin sensitivity. Serotyping was undertaken using a latex agglutination technique, as described previously (Hill et al., 2006, 2008). Equivocal results were confirmed by the Quellung reaction. The MRC microbiology laboratory results were submitted to the external quality assurance programme of the UK National External Quality Assessment Service (http://www.ukneqas. org.uk).

Semi-quantitative pneumococcal load. Semi-quantitative measurements of pneumococcal load were determined as recommended by the World Health Organization (O'Brien \& Nohynek, 2003) and recorded as $4+$ if 10 or more colonies were in quadrant $4,3+$ if there were fewer than 10 colonies in quadrant 4 and more than 10 colonies in quadrant $3,2+$ if there were fewer than 10 colonies in quadrant 3 and more than 10 colonies in quadrant 2 , and $1+$ if there were fewer than 10 colonies in quadrant 2 but growth in quadrant 1 .

Genomic DNA extraction. Genomic DNA templates were prepared from $100 \mu \mathrm{l}$ nasopharyngeal swab samples and Streptococcus pneumoniae isolates following the manufacturer's instructions (QIAamp Genomic DNA kit; Qiagen). Prior to purification of genomic DNA from pure Streptococcus pneumoniae, Streptococcus pneumoniae isolates were streaked on blood agar and incubated at $37{ }^{\circ} \mathrm{C}$ for $18 \mathrm{~h}$. A single colony from each isolate was picked, restreaked and incubated at $37{ }^{\circ} \mathrm{C}$ for $18 \mathrm{~h}$. Genomic DNA templates were prepared from a loopful of bacteria.

Sequential multiplex PCR assay. The serotype-specific primers were grouped into seven multiplex reactions (Fig. 1), as described previously (Pai et al., 2006). PCRs were performed in $20 \mu \mathrm{l}$ using ReddyMix PCR Master Mix (ABgene) containing primers at concentrations specified previously (Pai et al., 2006). The 29 primer pairs were used to target serotypes $1,3,4,5,6 \mathrm{~A} / \mathrm{B}, 7 \mathrm{~F}, 7 \mathrm{C}, 8,9 \mathrm{~V}, 10 \mathrm{~A}$, 11A, 12F, 14, 15A, 15B/C, 16F, 17F, 18, 19A, 19F, 20, 22F, 23F, 31, $33 \mathrm{~F}, 34,35 \mathrm{~B}, 35 \mathrm{~F}$ and 38 . The primer pair $c p s A-\mathrm{f} / c p s A-\mathrm{r}$ targeting the $c p s A$ gene found in all pneumococci was also included as an internal control. Purified DNA $(1.0 \mu \mathrm{l})$ from nasopharyngeal swabs or $1 \mathrm{ng}$ pneumococcal DNA was used in the PCR mixture. PCR cycling conditions were $10 \mathrm{~min}$ at $94{ }^{\circ} \mathrm{C}$, followed by 30 cycles of $94{ }^{\circ} \mathrm{C}$ for $45 \mathrm{~s}, 54{ }^{\circ} \mathrm{C}$ for $45 \mathrm{~s}$ and $65{ }^{\circ} \mathrm{C}$ for $2 \mathrm{~min} 30 \mathrm{~s}$, with a final extension at $65{ }^{\circ} \mathrm{C}$ for $10 \mathrm{~min}$, on a DNA Engine PTC-200 thermal cycler (MJ Research). Ten microlitres of each reaction mixture was separated by $1.5 \%$ agarose gel electrophoresis and visualized with ethidium bromide staining and UV illumination using a Gel Doc $2000 \mathrm{Gel}$ Documentation System (Bio-Rad).

Sensitivity and specificity of sequential multiplex PCR. To assess the limit of serotype detection, tenfold serial dilutions were made from pneumococci cultures and used for PCR followed by gel analysis. Twenty-nine clinical isolates of pneumococci representing different serotypes described previously (Antonio et al., 2008) were used as controls to test the primer specificity and to determine crossreactivity. The serotypes included 1, 2, 4, 5, 6A, 6B, 8, 9L, 9V, 12B, $12 \mathrm{~F}, 14,16 \mathrm{~F}, 18 \mathrm{C}, 18 \mathrm{~F}, 19 \mathrm{~A}, 19 \mathrm{~F}, 20,21,22 \mathrm{~A}, 23 \mathrm{~F}, 29,33 \mathrm{~F}, 35 \mathrm{~A}, 35 \mathrm{~B}$, $38,40,45$ and 46 .

To investigate the ability to detect multiple serotypes simultaneously, multiplex PCR was used to analyse mixed pneumococcal DNA that contained the serotypes $35 \mathrm{~B}$ and $18 \mathrm{~F}$ serotypes in varying ratios.

In total, 279 nasopharyngeal swab samples known to contain pneumococci obtained from children and adults during the crosssectional study (Hill et al., 2006) were chosen for a blinded study to evaluate the multiplex assay.

Statistical analysis. The Wilcoxon sign-rank test was used to compare the number of pneumococci identified by the different serotyping methods from the same samples. Both mean and median numbers of pneumococci are presented, as the non-parametric test can detect a difference in distribution, even if the medians are identical but one distribution has a long tail (and therefore a larger mean). As the molecular method could only identify 29 serotypes, two sets of analyses were performed: one comparing pneumococci using the conventional method and another comparing pneumococci belonging to the 29 serotypes using the conventional method against the molecular method. The binomial probability test was used to assess whether there were particular serotypes that were more likely to be identified by one method but not the other.

\section{RESULTS AND DISCUSSION}

Accurately detecting and identifying pneumococcal serotypes directly from nasopharyngeal swab samples is the cornerstone for interpretation of results of pneumococcal conjugate vaccine trials to detect serotype replacement (if it occurs). Current methods used to identify pneumococci are expensive, cumbersome, labour-intensive and inadequate for the detection of multiple serotypes of pneumococci. We believe that this study is the first to evaluate the 


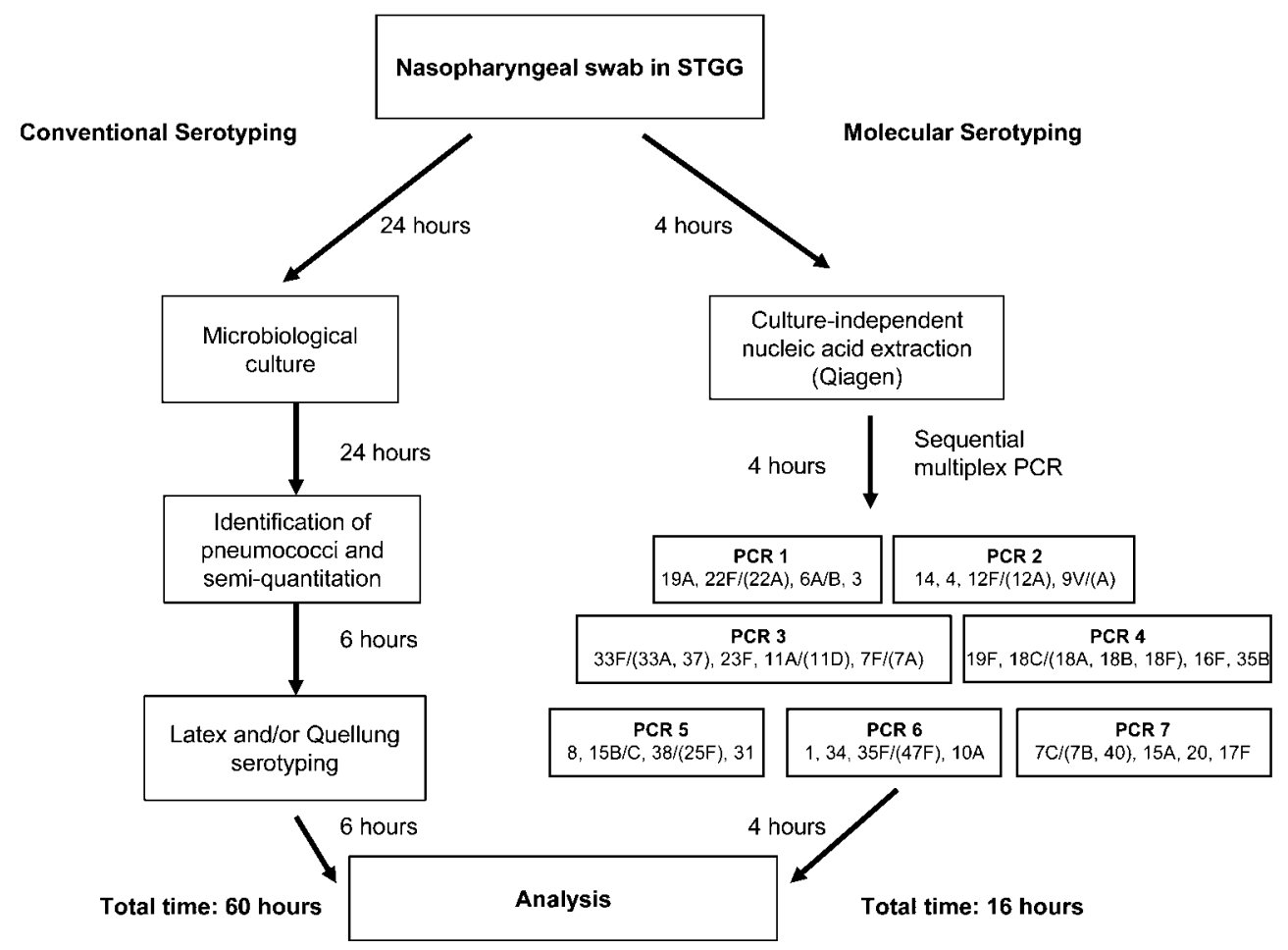

Fig. 1. Schematic representation of the conventional and molecular serotyping methods used in this study. Serotype 5 primers were excluded from any of the sequential multiplex reactions.

sequential multiplex PCR of Pai et al. (2006) for detection of pneumococcal serotypes directly from nasopharyngeal swab specimens and was carried out during a pneumococcal conjugate vaccine trial in The Gambia, a community with a high carriage rate of pneumococci (Hill et al., 2006).

The objective of this study was to develop a method that would allow analysis of 29 serotypes in a mixed pneumococcal population, thus giving a real perspective of the population occupying this niche. To achieve this, we eliminated the culture and enrichment steps prior to DNA extraction from the nasopharyngeal swabs. We believe that by culturing and enriching the nasopharyngeal swabs, the minority serotypes among the total pneumococcal population would be difficult to detect or would be masked by the majority serotypes, resulting in an underestimate of the prevalence of multiple pneumococcal serotypes. Therefore, DNA was extracted directly from nasopharyngeal swab samples using a QIAamp kit prior to PCR detection for the presence of pneumococci. The reliability of detection by multiplex PCR was addressed by including an internal control in all reactions which targeted the $\operatorname{cps} A$ gene, a highly conserved gene of the capsular loci of Streptococcus pneumoniae (Pai et al., 2006). This locus was amplified in all of the pneumococci included in this study.

The sensitivity of the multiplex PCR assay was determined using serial dilutions of pneumococci cultures and colony counting. The lower limit of pneumococcus detection was
$1 \times 10^{3}$ cells $(\mathrm{ml} \text { sample })^{-1}$. To investigate the ability to detect multiple serotypes simultaneously, multiplex PCR was used to analyse mixed (spiked) pneumococcal DNA that contained serotypes $35 \mathrm{~B}$ and $18 \mathrm{~F}$ in varying ratios. The lower limit of pneumococcus detection was $1 \mathrm{ng}$ DNA $\mu \mathrm{l}^{-1}$ (data not shown).

The specificity of the sequential multiplex assay was tested using representative Streptococcus pneumoniae serotypes not included in the 29 serotypes tested and nonStreptococcus pneumoniae Gram-positive and Gram-negative bacteria for detection of cross-reactivity. These included Streptococcus pyogenes, Streptococcus agalactiae, Staphylococcus aureus, Staphylococcus epidermidis, Moraxella catarrhalis, Haemophilus influenzae, Mycobacterium tuberculosis and Neisseria meningitidis groups A and B. No cross-reactivity was detected using Streptococcus pneumoniae species-specific $(c p s A)$ and serotype-specific primers (Pai et al., 2006) (data not shown).

A total of 279 nasopharyngeal samples were examined using the sequential multiplex PCR; 182 samples (65.2\%) were $c p s A$-positive (see Fig. 2 for a representative gel). The cpsA-negative samples were excluded from further analysis. Table 1 provides the descriptive statistics of the number of pneumococci identified per typing method and the total number of serotypes per sample identified in the $182 \operatorname{cps} A$ positive samples. The latex/Quellung serotyping method detected a mean value of 1.20 serotypes per sample, which 

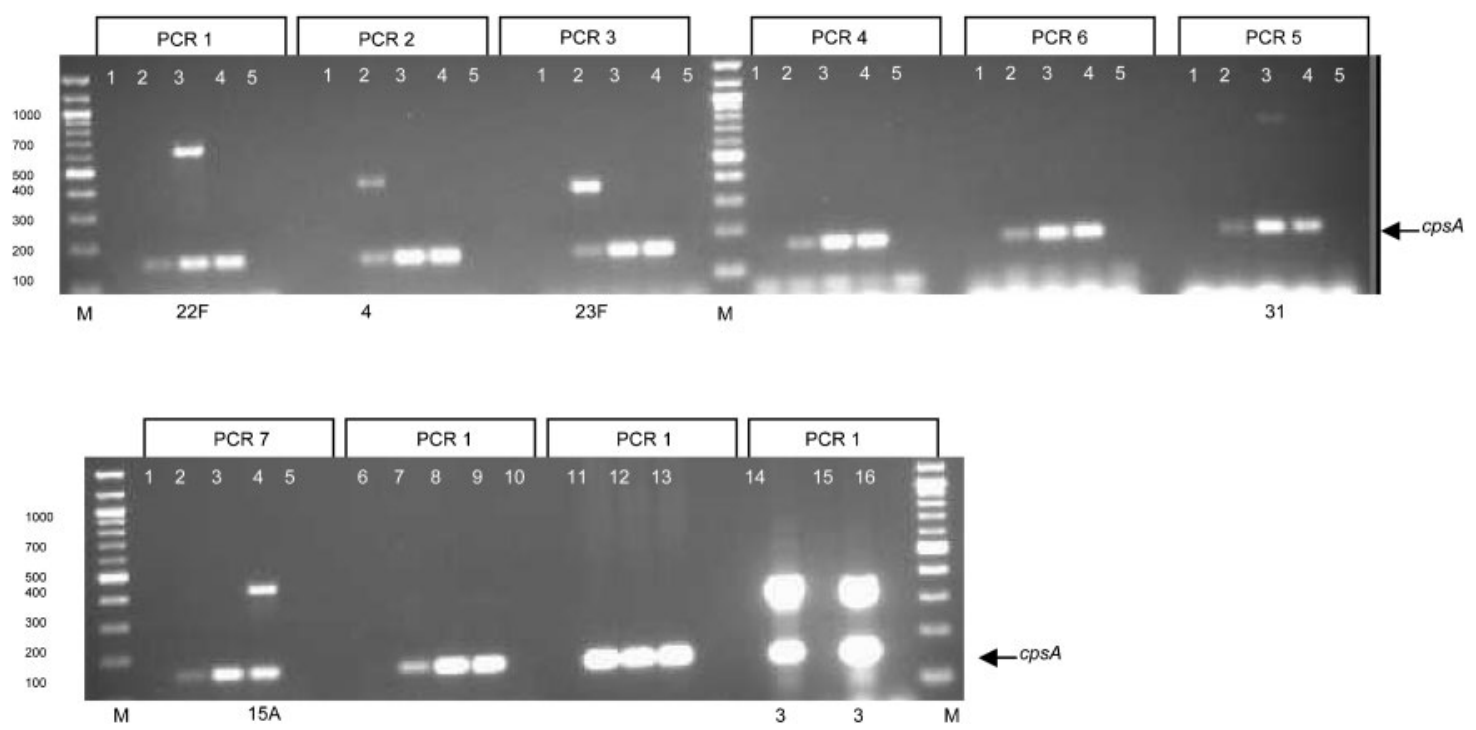

Fig. 2. Representative sequential multiplex PCRs carried out directly from nasopharyngeal swab samples. Lanes: $M, 100$ bp ladder; 1 and 6, negative controls (no template); 2-4, nasopharyngeal swab samples; 5 and 10, negative controls (Staphylococcus aureus); 7-9 and 11-13, pneumococci not included in the assay; 14 and 15, serotype 3 (positive controls for reaction 1). The specific serotypes identified in the swab samples by PCR are indicated below the lanes.

was significantly higher than the mean value of 1.01 from the multiplex PCR method $(P=0.0001)$. However, when limited to the 29 serotypes identifiable by the multiplex PCR method, the mean number of serotypes per sample found by the latex/Quellung method was 0.85 , which was significantly lower than that by the molecular method ( $P$ $<0.0001)$. Therefore, when limited to these 29 serotypes, the multiplex PCR method identified significantly more serotypes than conventional serotyping. As far as individual serotypes were concerned, there was evidence $(P=0.063)$ that the multiplex PCR method was more sensitive for the detection of serotype 23F.

The relative performance of the two methods differed according to the pneumococcal load in the nasopharyngeal swab samples. The performance of the multiplex PCR method was improved when the pneumococcal load density was 3 or 4 due to a larger number of pneumococci cells and hence DNA. The numbers of samples with densities of $1,2,3$ and 4 were 13,41, 82 and 42 ,

Table 1. Number of serotypes per sample $(n=182)$ identified by conventional and molecular serotyping

\begin{tabular}{|lccccc|}
\hline Method & Mean & Median & Minimum & Maximum & Total \\
\hline Latex/Quellung & 1.20 & 1 & 1 & 3 & 218 \\
Latex/Quellung, limited to 29 serotypes & 0.85 & 1 & 0 & 3 & 154 \\
Multiplex PCR & 1.01 & 1 & 0 & 3 & 184 \\
\hline
\end{tabular}

Table 2. Mean number of serotypes per sample $(n=178)$ identified by conventional and molecular serotyping, analysed by colony density

\begin{tabular}{|c|c|c|c|c|c|}
\hline \multirow{2}{*}{$\begin{array}{l}\text { Colony density } \\
\text { (semi-quantitative) }\end{array}$} & \multicolumn{3}{|c|}{ Mean number of serotypes per sample } & \multicolumn{2}{|c|}{$P$ value of molecular method versus: } \\
\hline & Latex/Quellung & $\begin{array}{l}\text { Latex/Quellung, limited } \\
\text { to } 29 \text { serotypes }\end{array}$ & Multiplex PCR & Latex/Quellung & $\begin{array}{l}\text { Latex/Quellung, limited } \\
\text { to } 29 \text { serotypes }\end{array}$ \\
\hline 1 or $2(n=54)$ & 1.11 & 0.76 & 0.74 & $<0.001$ & 0.978 \\
\hline $3(n=82)$ & 1.27 & 0.98 & 1.15 & 0.106 & 0.001 \\
\hline $4(n=42)$ & 1.17 & 0.90 & 1.07 & 0.188 & 0.014 \\
\hline
\end{tabular}


Table 3. Serotype distribution by conventional and molecular methods

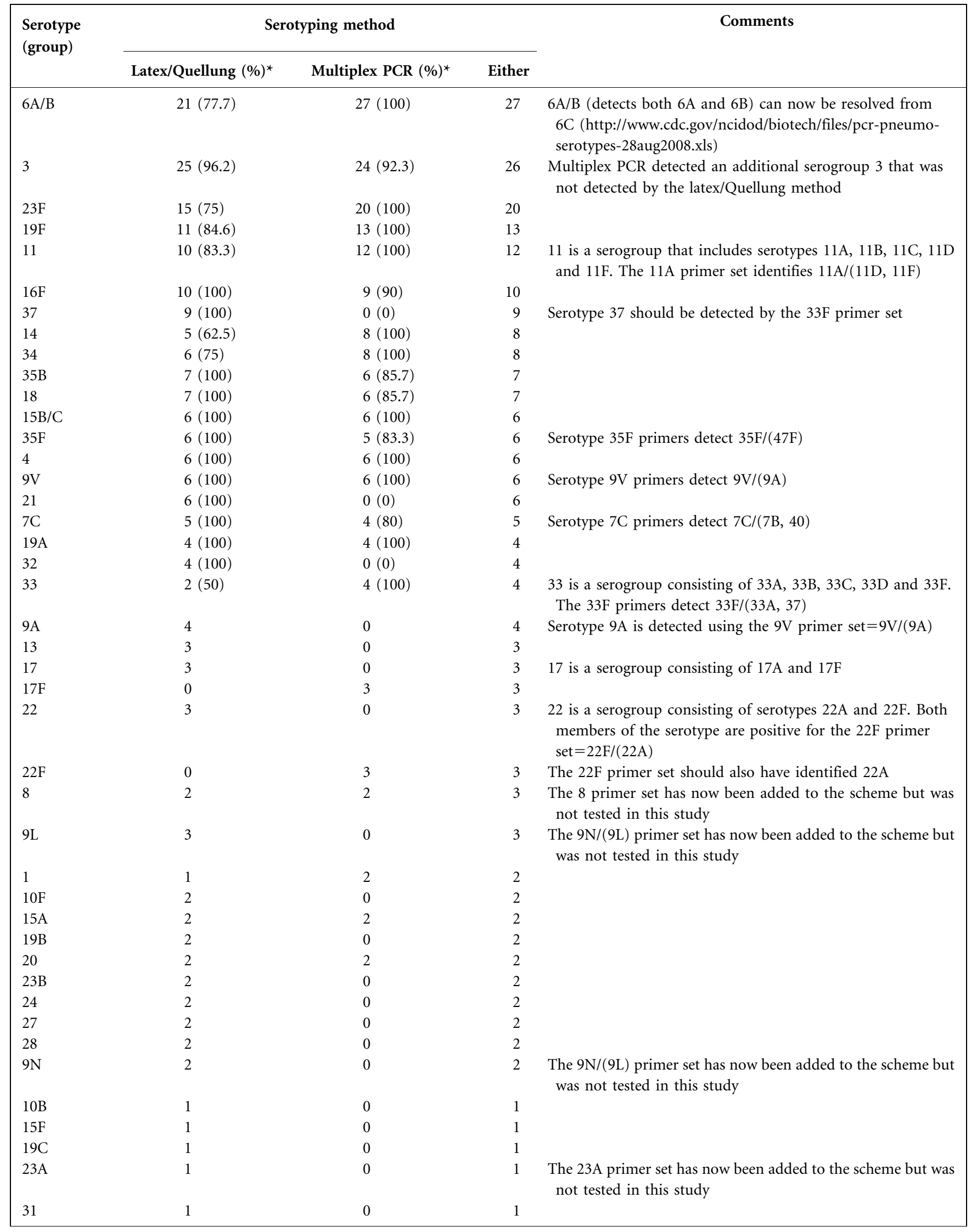


Table 3. cont.

\begin{tabular}{|c|c|c|c|c|}
\hline \multirow{2}{*}{$\begin{array}{l}\text { Serotype } \\
\text { (group) }\end{array}$} & \multicolumn{3}{|c|}{ Serotyping method } & \multirow[t]{2}{*}{ Comments } \\
\hline & Latex/Quellung $(\%)^{\star}$ & Multiplex PCR $(\%)^{*}$ & Either & \\
\hline 36 & 1 & 0 & 1 & \\
\hline 38 & 1 & 0 & 1 & $\begin{array}{l}\text { Serotype } 38 \text { apparently is often } c p s A \text {-negative (http:// } \\
\text { www.cdc.gov/ncidod/biotech/files/pcr-pneumo-serotypes- } \\
\text { 28aug2008.xls) }\end{array}$ \\
\hline 5 & 1 & 1 & 1 & \\
\hline 7F & 1 & 1 & 1 & \\
\hline Total & 218 & 184 & 249 & \\
\hline
\end{tabular}

${ }^{*}$ The percentage value is indicated in parentheses for the top 20 serotypes.

respectively. Four samples had no colony density recorded. The median number of serotypes found by the multiplex PCR method and the latex/Quellung method (with or without limiting to the 29 serotypes) was 1 . Table 2 shows the mean number of serotypes per sample. Among samples with a density of 1 or 2 , the multiplex PCR method identified a smaller number $($ mean $=0.74)$ of serotypes than the latex/Quellung method (mean $=1.11 ; P<0.001$ ). There was no significant difference between the multiplex PCR method and the latex/Quellung method when limited to the 29 serotypes $(P=0.978)$. In contrast, among samples with a density of 3 or 4 , the mean number of serotypes found was not significantly different between the latex/ Quellung and multiplex PCR methods $(P=0.106$ and $P=0.188$, respectively), whilst the multiplex PCR method found significantly more serotypes than the latex/Quellung method when limited to the 29 serotypes $(P=0.001$ and $P=0.014$, respectively).

When limited to the 29 serotypes/groups, the latex/ Quellung and multiplex PCR methods identified 154 and 184 serotypes, respectively (Table 1 ). However, using both methods, 249 serotypes were found, targeting all 91 serotypes. Table 3 shows the serotype distribution by methods. Note that some serotypes have been grouped for comparability between methods, i.e. $6 \mathrm{~A}$ and $6 \mathrm{~B}$ from the latex/Quellung serotyping method have been grouped as $6 \mathrm{~A} / \mathrm{B}, 15 \mathrm{~B}$ and $15 \mathrm{C}$ from the latex/Quellung method have been grouped as $15 \mathrm{~B} / \mathrm{C}$, serotypes in the 18 group in latex/ Quellung typing have been grouped as serogroup 18, and serotypes in the 11 group in the multiplex PCR method have been grouped as serogroup 11 .

A binomial probability test was used to assess whether there were any serotypes that were more likely to be identified by multiplex PCR or latex/Quellung serotyping. Serotype $23 \mathrm{~F}$ was found in 15 samples by both methods and in five additional samples by the multiplex PCR method only $(P=0.063)$. Tests for the other serotypes all gave $P$ values greater than 0.1 .
When both methods were used, the number of serotypes detected was 249, compared with 218 based on the conventional latex/Quellung method alone and 184 based on the molecular method alone. It is therefore appropriate to consider these two methods as complementary. In addition, when limited to the 29 serotypes, the conventional latex/Quellung serotyping method detected 16 and $3.1 \%$ double and triple serotypes, respectively, whereas the sequential multiplex PCR assay method detected 27 and $5 \%$ double and triple serotypes, respectively.

The limitation of this study is that the sequential multiplex PCR assay can only detect 29 serotypes compared with 91 (plus non-typable) from the conventional latex/Quellung methods. In addition, we were only able to detect $24 / 26$ of serotype 3 , and $6 / 7$ of serotypes 18 and $35 \mathrm{~B}$ (Table 3 ), although they were all $c p s A$-positive and repeating these by conventional serotyping showed the presence of these serotypes. However, the fact that highly purified template DNA was extracted directly from nasopharyngeal swabs with minimum effort and time, and that pure bacterial culture was not required for this sequential multiplex PCR, enhances the likelihood of successfully utilizing this assay in laboratories lacking bacterial culture facilities.

\section{ACKNOWLEDGEMENTS}

We would like to acknowledge Ebou Mbowe and Lamin Juwara for technical assistance and the MRC (UK) for funding this project.

\section{REFERENCES}

Antonio, M., Dada-Adegbola, H., Biney, E., Awine, T., O'Callaghan, J., Pfluger, V., Enwere, G., Okoko, B., Oluwalana, C. \& other authors (2008). Molecular epidemiology of pneumococci obtained from Gambian children aged 2-29 months with invasive pneumococcal disease during a trial of a 9 -valent pneumococcal conjugate vaccine. BMC Infect Dis 8, 81 .

Berkley, J. A., Lowe, B., Mwangi, I., Williams, T., Bauni, E., Mwarumba, S., Ngetsa, C, Slack, M. P., Njenga, S. \& other authors 
(2005). Bacteremia among children admitted to a rural hospital in Kenya. N Engl J Med 352, 39-47.

Berman, S. (1995). Otitis media in children. N Engl J Med 332, 15601565.

Dagan, R., Givon-Lavi, N., Zamir, O. \& Fraser, D. (2003). Effect of a nonvalent conjugate vaccine on carriage of antibiotic-resistant Streptococcus pneumoniae in day-care centres. Pediatr Infect Dis J 22, 532-540.

Dias, C. A., Teixeira, L., Carvalho, M. G. \& Beall, B. (2007). Sequential multiplex PCR for determining capsular serotypes of pneumococci recovered from Brazilian children. J Med Microbiol 56, 1185-1188.

Enwere, G., Biney, E., Cheung, Y., Zaman, S., Okoko, B., Oluwalana, C., Vaughan, A., Greenwood, B., Adegbola, R. \& other authors (2006). Epidemiologic and clinical characteristics of community-acquired invasive bacterial infections in children aged 2-29 months in The Gambia. Pediatr Infect Dis J 25, 700-705.

Frederiksen, B. \& Henrichsen, J. (1988). Throat carriage of Streptococcus pneumoniae and Streptococcus pyogenes among infants and children in Zambia. J Trop Pediatr 34, 114-117.

Ghaffar, F., Barton, T., Lozano, J., Muniz, L., Hicks, P., Gan, V., Ahmad, N. \& McCracken, G. J. (2004). Effect of the 7-valent pneumococcal conjugate vaccine on nasopharyngeal colonization by Streptococcus pneumoniae in the first 2 years of life. Clin Infect Dis 39, 930-938.

Gratten, M., Gratten, H., Poli, A., Carrad, E., Raymer, M. \& Koki, G. (1986). Colonisation of Haemophilus influenzae and Streptococcus pneumoniae in the upper respiratory tract of neonates in Papua New Guinea; primary acquisition, duration of carriage, and relationship to carriage in mothers. Biol Neonate 50, 114-120.

Gray, B. M., Converse, G., III \& Dillon, H., Jr (1980). Epidemiologic studies of Streptococcus pneumoniae in infants: acquisition, carriage and infections during the first 24 months of life. J Infect Dis 142, 923933.

Greenwood, B. (1999). The epidemiology of pneumococcal infection in children in the developing world. Philos Trans R Soc Lond B Biol Sci 354, 777-785.

Hausdorff, W. P., Bryant, J., Paradiso, P. \& Siber, G. (2000). Which pneumococcal serogroups cause the most invasive disease: implications for conjugate vaccine formulation and use. Clin Infect Dis 30, $100-121$.

Hill, P. C., Akisanya, A., Sankareh, K., Cheung, Y., Saaka, M., Lahai, G., Greenwood, B. \& Adegbola, R. (2006). Nasopharyngeal carriage of Streptococcus pneumoniae in Gambian villagers. Clin Infect Dis 43, 673-679.

Hill, P. C., Cheung, Y., Akisanya, A., Sankareh, K., Lahai, G., Greenwood, B. \& Adegbola, R. (2008). Nasopharyngeal carriage of Streptococcus pneumoniae in Gambian infants: a longitudinal study. Clin Infect Dis 46, 807-814.

Jones, N., Huebner, R., Khoosal, M., Crewe-Brown, H. \& Klugman, K. (1998). The impact of HIV on Streptococcus pneumoniae bacteraemia in a South African population. AIDS 12, 2177-2184.

Klugman, K. P. (2001). Efficacy of pneumococcal conjugate vaccines and their effect on carriage and antimicrobial resistance. Lancet Infect Dis 1, 85-91.
Lloyd-Evans, N., O’Dempsey, T., Baldeh, I., Secka, O., Demba, E., Todd, J., McArdle, T., Banya, W. \& Greenwood, B. (1996). Nasopharyngeal carriage of pneumococci in Gambian children and in their families. Pediatr Infect Dis J 15, 866-871.

Madhi, S. A., Petersen, K., Madhi, A., Wasas, A. \& Klugman, K. (2000). Impact of human immunodeficiency virus type 1 on the disease spectrum of Streptococcus pneumoniae in South African children. Pediatr Infect Dis J 19, 1141-1147.

Mbelle, N., Huebner, R., Wasas, A., Kimura, A., Chang, I. \& Klugman, K. (1999). Immunogenicity and impact on nasopharyngeal carriage of a nonavalent pneumococcal conjugate vaccine. J Infect Dis 180, 1171-1176.

Morais, L., Carvalho, M. G., Roca, A., Flannery, B., Mandomando, I., Soriano-Gabarró, M., Sigauque, B., Alonso, P. \& Beall, B. (2007). Sequential multiplex PCR for identifying pneumococcal capsular serotypes from South-Saharan African clinical isolates. $\mathrm{J} \mathrm{Med}$ Microbiol 56, 1181-1184.

Obaro, S. K., Adegbola, R., Banya, W. \& Greenwood, B. (1996). Carriage of pneumococci after pneumococcal vaccination. Lancet 348, 271-272.

Obaro, S. K., Adegbola, R., Chang, I., Banya, W., Jaffar, S., McAdam, K. \& Greenwood, B. (2000). Safety and immunogenicity of a nano-valent pneumococcal vaccine conjugated to CRM197 administered simultaneously but in a separate syringe with diphtheria, tetanus and pertussis vaccine in Gambian infants. Pediatr Infect Dis J 19, 463-469.

O’Brien, K. L. \& Nohynek, H. (2003). Report from a WHO Working Group: standard method for detecting upper respiratory carriage of Streptococcus pneumoniae. Pediatr Infect Dis J 22, 133-140.

O'Brien, K. L., Moulton, L., Reid, R., Weatherholtz, R., Oski, J., Brown, L., Kumar, G., Parkinson, A., Hu, D. \& other authors (2003). Efficacy and safety of seven-valent conjugate pneumococcal vaccine in American Indian children: group randomised trial. Lancet 362, 355361.

Pai, R., Gertz, R. \& Beall, B. (2006). Sequential multiplex PCR approach for determining capsular serotypes of Streptococcus pneumoniae isolates. J Clin Microbiol 44, 124-131.

Park, I. H., Pritchard, D., Cartee, R., Brandao, A., Brandileone, M. \& Nahm, M. (2007). Discovery of a new capsular serotype (6C) within serogroup 6 of Streptococcus pneumoniae. J Clin Microbiol 45, 12251233.

Scott, J. A. (2007). The preventable burden of pneumococcal disease in the developing world. Vaccine 25, 2398-2405.

Scott, J. A., Brooks, W., Peiris, J., Holtzman, D. \& Mulholland, E. (2008). Pneumonia research to reduce childhood mortality in developing world. J Clin Invest 118, 1291-1300.

Shann, F. (1986). Etiology of severe pneumonia in children in developing countries. Pediatr Infect Dis 5, 247-252.

Syrjären, R. K., Auranen, K., Leino, T., Kilpi, T. \& Mäkelä, P. (2005). Pneumococcal acute otitis media in relation to pneumococcal nasopharyngeal carriage. Pediatr Infect Dis J 24, 801-806.

Whitney,, C. G., Farley, M. M., Hadler, J., Harrison, L. H., Bennett, N. M., Lynfield, R., Reingold, A., Cieslak, P. R., Pilishvili, T. \& other authors (2003). Decline in invasive pneumococcal disease after the introduction of protein-polysaccharide conjugate vaccine. $N$ Engl J Med 348, 1737-1746. 